\title{
Article
}

\section{Remote Prescribing}

\author{
Broadhead, Ruth
}

Available at http://clok.uclan.ac.uk/34094/

Broadhead, Ruth (2020) Remote Prescribing. Journal of Prescribing Practice, 2 (7). pp. 380-382. ISSN 2631-8385

It is advisable to refer to the publisher's version if you intend to cite from the work. https://doi.org/10.12968/jprp.2020.2.7.380

For more information about UCLan's research in this area go to

http://www.uclan.ac.uk/researchgroups/ and search for < name of research Group>.

For information about Research generally at UCLan please go to http://www.uclan.ac.uk/research/

All outputs in CLoK are protected by Intellectual Property Rights law, including Copyright law. Copyright, IPR and Moral Rights for the works on this site are retained by the individual authors and/or other copyright owners. Terms and conditions for use of this material are defined in the policies page.

\section{CLoK}

Central Lancashire online Knowledge www.clok.uclan.ac.uk

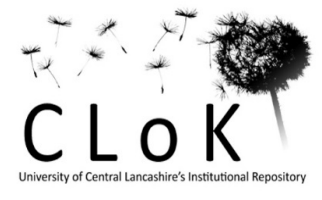




\section{Calculation skills for all prescribers - Remote Prescribing}

Author:

Ruth Broadhead

Senior Lecturer

Programme Lead: Non-Medical Prescribing

University of Central Lancashire

It is a stipulation of the professional bodies that Non-Medical Prescribers are accountable and responsible for their own decisions in respect of safe, patient-centred care, including prescribing (Nursing \& Midwifery Council, 2018; Health \& Care Professions Council, 2016; General Pharmaceutical Council, 2017). A collaboration in 2019 between the Medical Royal Colleges, healthcare regulators and other professional organisations identified ten high level principles that are fundamental to safe, good quality remote consultations and prescribing. Within the current climate of an NHS that is adapting to the Covid-19 pandemic, this collaborative guidance could not have been more timely. The Royal Colleges et al (2019) identify that remote consultations and prescribing can provide benefit to patients, save finite resources and promote convenient access to healthcare services. However, they stipulate that safeguards must be in place before the prescriber considers this mechanism of providing medication to our patients.

Broadhead (2020) describes remote prescribing as that which occurs in the context of the prescriber and the patient being physically or geographically remote from each other. Its success is dependent on robust consultation techniques including gaining valid consent, building effective dialogue, fostering rapport, accurate history taking and observation of the patient when required. In order to maintain safety, within the Royal Pharmaceutical Society (2016) A competency framework for all prescribers, the Prescribing Governance domain, competence 7.1, advises that the prescriber "identifies the potential risks associated with prescribing via remote media (telephone, email or through a third party) and takes steps to minimise them". Williams, (2019) suggests that whilst being physically absent from the patient is not ideal in every circumstance, remote prescribing has ultimately improved patient care for some. He does advocate, however, that to ensure patient safety is not compromised, the 
development of protocols and the undertaking of robust risk assessment are essential components of remote prescribing. Williams (2019) further states that working remotely still allows the prescriber to issue electronic prescriptions, order and interpret investigations, manage long-term conditions and undertake medication reviews by telephone. This said, Raymond (2019) suggests that it is paramount that remote prescribing is undertaken with caution and in accordance with the guidance from the Medical Defence Union (MDU) (2018). The MDU urges prescribers to consider the following: you are satisfied that you are in a position to prescribe safely; are prepared to ask the patient to come in for a physical examination; have adequate knowledge of the patient's health and that you are satisfied the medication you prescribe serves the patient's needs.

Reflect on your own prescribing role and consider the scenarios and calculations below:

\section{Question 1}

James is 65 years old and currently shielding. You have managed this patient for many years in Primary Care and know his condition and treatment regime well. You undertake a telephone consultation at James' request and subsequently diagnose an infective exacerbation of COPD. You prescribe antibiotics and oral steroids as follows:

Amoxicillin 500mg capsules - one capsule three times a day ( 8 hourly) for 7 days

Prednisolone $5 \mathrm{mg}$ tablets -6 tablets daily in the morning for 7 days

a. What is the daily dose of amoxicillin in $g$ ?

b. How many capsules of amoxicillin should be supplied in total

c. What is the total daily dose of prednisolone in $\mathrm{mg}$ ?

d. How many tablets of prednisolone need to be supplied for 7 days?

\section{Question 2}

Marc is 34 and attended A\&E two days ago following a fall from his mountain bike. An X-Ray showed no bony injury and a soft tissue injury was diagnosed. He was advised to take paracetamol $500 \mathrm{mg}$ tablets $\times 2$ every 4-6 hours for pain relief (maximum 8 tablets in 24 hours). During your remote consultation today, he explained that, despite 
taking the maximum dose of paracetamol, his pain was still moderate to severe. You take a comprehensive history and decide that adding an NSAID would be beneficial. As there are no contraindications to this medication, you prescribe lbuprofen $200 \mathrm{mg}$ tablets at 1-2 tablets every 6 hours for the next 7 days, but advise him to purchase these over the counter.

a. If Marc is taking the maximum dose of $8 \times$ paracetamol tablets every 24 hours, how many tablets will he consume over 2 weeks?

b. Marc has an unopened box of paracetamol $500 \mathrm{mg}$ tablets at home. It contains 30 tablets. If he takes paracetamol as prescribed for the next 10 days, how many more boxes of 30 tablets will he need to purchase?

c. How many paracetamol will Marc have left after 10 days treatment?

d. Assuming Marc takes the maximum prescribed dose of ibuprofen $(200 \mathrm{mg} \times 2$ tablets every 6 hours), how many tablets will Marc need for 7 days treatment?

\section{Question 3}

Jeff, aged 46 has Hashimoto's thyroiditis. He has been taking thyroxine 150micrograms daily for the last 12 months. You have the results of his last thyroid function tests (TFT) which show an elevated thyroid-stimulating hormone (TSH) and a low T4. You undertake a telephone consultation with Jeff to discuss an increase in treatment. It is agreed that Jeff should now take 200 micrograms thyroxine daily. You prescribe Levothyroxine sodium 100microgram tablets, two daily in the morning.

a. Jeff currently has $60 \times 50$ microgram tablets and $60 \times 100$ microgram tablets in stock. How many days' supply of thyroxine does Jeff have if he uses all of these before requiring a new prescription?

b. How many 100 microgram tablets will Jeff require for 28 days' treatment on his new dose?

You arrange to check Jeff's TFTs in 6 months. Levothyroxine 100microgram tablets cost $£ 1.50$ for 28 tablets.

c. Assuming one calendar month is 28 days, what is the total cost of this medication for a six-month period?

d. If Jeff's dose is then subsequently increased by $25 \%$, what would the new daily dose of thyroxine be? 


\section{Question 4}

Mary, aged 26 is a registered nurse and requests a telephone consultation with you this morning. She is complaining of recurrent urinary symptoms. Mary had undertaken urinalysis at work yesterday and this was positive for leucocytes and nitrites using Multistix ${ }^{\circledast}$. You are satisfied that antibiotics are required for Mary, she is not pregnant or breastfeeding and you have a choice to prescribe immediate release or modified release Nitrofurantoin. In order to promote concordance, the treatment plan was discussed with Mary, offering either:

Option 1: Nitrofurantoin 50mg tablets (immediate release) 1 tablet four times a day for 7 days

or

Option 2: Nitrofurantoin 100mg capsules (modified release) 1 capsule twice a day for 7 days

a. How many immediate release tablets would need to be supplied for Mary?

b. How many modified release capsules would need to be supplied for Mary?

c. If immediate release tablets cost $£ 35.00$ per 28 tablets and modified release capsules cost $£ 10.42$ per 30 capsules, which regime is the most cost-effective?

d. When prescribing Option 2, how much Nitrofurantoin (in g) would be taken in total by Mary over the 7-day period?

\section{Question 5}

Daniel, aged 56 received a diagnosis of Stage 1 hypertension two years ago. He was initially prescribed an ACE inhibitor but has not been compliant with the regime for approximately 6 months. Daniel has been recording his blood pressure twice daily as you requested and he demonstrates a correct technique to you today during the Skype consultation. The readings indicate that treatment is required. He has no renal impairment or other contraindication to recommencing an ACE inhibitor. You decide to commence Ramipril $2.5 \mathrm{mg}$ tablets once daily and review him in 2 weeks. 
a. How many Ramipril $2.5 \mathrm{mg}$ tablets will you prescribe for 2 weeks?

b. How many mg of Ramipril will Daniel have taken over 1 week?

After 2 weeks, Daniel's blood pressure remains uncontrolled. You increase the strength of Ramipril by $100 \%$.

c. What is the strength of Ramipril you now prescribe?

d. How many mg of Ramipril will Daniel consume until his next review in 28 days?

\section{$\underline{\text { References (APA } 6^{\text {th }} \text { Edition) }}$}

Academy of Medical Royal Colleges, Care Quality Commission, Faculty of Pain Medicine, General Dental Council, General Medical Council, General Optical Council, General Pharmaceutical Council, Healthcare Improvement Scotland, Healthcare Inspectorate Wales, Nursing and Midwifery Council, Pharmaceutical Society of Northern Ireland, Royal Pharmaceutical Society, Regulation and Quality Improvement Authority (2019) High level principles for good practice in remote consultations and prescribing. Retrieved from www.nmc.org and www.pharmacyregulation.org

Broadhead, R. (2020) Professional, legal \& ethical issues in prescribing practice. In: Nuttall, D. \& Rutt-Howard, J. (2020) The Textbook of Non-Medical Prescribing. Chichester. Wiley Blackwell.

General Pharmaceutical Council (2017) Standards for pharmacy professionals. London: GPhC

Health \& Care Professions Council (2016) Standards of Conduct, performance and ethics. London: HCPC

Medical Defence Union (2018) Prescribing. Retrieved from https://www.themdu.com/guidance-and-advice/guides/prescribing

Nursing \& Midwifery Council (2018) The Code: Professional standards of practice and behaviour for nurses, midwives and nursing associates. London: NMC

Raymond, S. (2019) Remote prescribing in the out of hours GP setting: The challenges and guidance: Part 2. Retrieved from:

https://www.gmjournal.co.uk/remote-prescribing-in-the-out-of-hours-gpsetting-the-challenges-and-guidance

Royal Pharmaceutical Society (2016) A competency framework for all prescribers. London: RPS

Williams, A. (2019) How our remote prescribing service has improved care. The Pharmaceutical Journal. Retrieved from https://www.pharmaceuticaljournal.com/news-and-analysis/opinion/blogs/how-our-remote-prescribingservice-has-improved-care/20206793.blog?firstPass=false 


\section{Answers}

Q1
a. $1.5 \mathrm{~g}$
b. 21 capsules
c. $30 \mathrm{mg}$
d. 42 tablets

Q2
a. 112 tablets
b. 2 boxes
c. 10 tablets
d. 56 tablets

Q3
a. 45 days (use $2 \times 100$ microgram tablets for 30 days then $4 \times 50$ microgram tablets for 15 days)
b. 56 tablets
c. $£ 9.00$
d. 250 micrograms

Q4
a. 28 tablets
b. 14 capsules
c. Option 2
d. $1.4 \mathrm{~g}$

Q5
a. 14 tablets
b. $17.5 \mathrm{mg}$
C. $5 \mathrm{mg}$
d. $140 \mathrm{mg}$ 